\title{
Patient Satisfaction With Health Care Services In Outpatient Depart- ment Of A Dental College Hospital In Pakistan
}

\author{
Soomro $\mathrm{M} \mathrm{H}^{1}$, Magsi $\mathrm{M}^{2}$, Lahmar $\mathrm{O}^{3}$ \\ Received: 20.10 .17 \\ Accepted: 07.04.18
}

\begin{abstract}
:
Introduction: Patient satisfaction is one of the important factors to determine the success of health care facility. The real challenge is not getting ready with mere requirements, but also delivers services ensuring good quality. Thus, there is a need to assess the health care systems regarding patient satisfaction as often as possible. The aim of this study was to determine the patient satisfaction with health care services in out-patient department (OPD) of a dental college hospital in Pakistan.

Materials and Methods: A descriptive cross-sectional pilot study was undertaken during the month of May 2015 in the OPD of Bibi Asifa Dental College and Hospital, Larkana, Pakistan. A randomly selected 100 patients were interviewed by using pre-structured questionnaires. The questionnaires had semi-structured, open-ended and closed questions. While analyzing, they were grouped into categories like availability of services, clinical care, waiting time and cost.

Results: The overall opinions about the satisfaction level of patients for availability of health services in the hospital were good. As location of the hospital and timings of the OPD were convenient to the most of the patients $86 \%$ and $93 \%$ respectively. Availability of the doctors was also found adequate. However, regarding seating arrangements one fourth of the total patients were found to be unsatisfied. Efficiency of the doctor was found satisfactory by $83 \%$, while majority of the patients did not faced any kind of language problem.

Conclusion: According to patient's opinion, the study revealed that the degree of satisfaction was satisfactory with respect to waiting time and availability of the doctors in the hospital, which need to be further explored and corrected.
\end{abstract}

Key Words: Patient satisfaction, dental outpatient department, health care.

1. Munawar Hussain Soomro, Department of Community Medicine, Al-Nafees Medical College, Isra University-Islamabad Campus, Pakistan.

2. Mansoor Magsi, Department of Medicine, ShaheedMohtarma Benazir Bhutto Medical University, Larkana, Pakistan.

3. Oussama Lahmar, University of Sciences Tunis, Tunis El Manar University, Tunisia.

Correspondence : Dr Munawar Hussain Soomro, Email: munawar.soomro@iplesp.upmc.fr, Tel No. +33783389545 


\section{Introduction}

Health care quality is a globally concerned issue. The main purpose of health care services is to provide quality of care and to improve health status of the population ${ }^{[1,2]}$. The scope of the health services varies widely from place to place and country to country. Further health services are influenced by general and ever changing national, state and local health problems, their needs, attitude and available resources to provide these services. History reveals that health care has seen many changes over the time according to the requirement of the society and availability of the resources and technologies.

In the recent years much attention has been paid to improve health care and decrease inequalities within the health care systems. Health system research is essential for the continuous evolution and refinement of health services. Nowadays managers and policy makers of health care systems are much more interested in the improvement of quality care ${ }^{[3,4]}$. Patient satisfaction is an individual's feeling of pleasure or disappointment resulting for comparing a service's perceived performance or outcome in relation to his or her expectations. Patient satisfaction has remained one of the most essential and important focus point for health care providers. Panchansky $R$ and Thomas JW, defined patient satisfaction as the degree of congruency between a patient's expectations of ideal nursing care and his perception of real nursing care that he or she received ${ }^{[5]}$. while Swan JE et.al suggested that patient satisfaction is a positive emotional response that is desired from a cognitive process in which patient compare their individual experience to a set of subjective standards ${ }^{[6]}$. It can be concluded that patient satisfaction happens when all needs are met according to their expectations. Patient satisfaction is essential due to the multiple reasons. Any unsatisfied patient will not come back to the hospital, and it will lead to loss of money of patient as well as wastage of resources. High satisfaction will indicate that hospital is working efficiently. On the other hand, poor satisfaction level will indicate management to improve the health services.

Presence of services in multiple specialties, attendance of out-patient department (OPD) by a large number of patients and allocation of huge resources demand that quality of care provided by the hospital should be determined. The most reliable tool availa- ble for this purpose is the finding the level of patient satisfaction. Only a satisfied patient can confirm the high quality of medical care provided by the OPD. Bibi Asifa Dental College and Hospital is a recently developed teaching dental hospital attached with Shaheed Mohtarma Benazir Bhutto Medical University, Larakana in Pakistan, providing dental health care services to the patients. Therefore, this study was designed to determine the patient satisfaction with health care services in OPD of the Dental college hospital.

\section{Materials and Methods}

A descriptive cross-sectional pilot study was undertaken during the month of May 2015 in the OPD of Bibi Asifa Dental College and Hospital, Larkana, Pakistan. In this pilot study a total number of 100 patients were interviewed by using simple random sampling technique. The main purpose was to determine the patient satisfaction with health care services in OPD of the dental college hospital. Patients aged 18 years and older were included in the study for interviews. Patients with age below 18 years (usually considered as children in Pakistan and many other countries), severe toothache and unwilling to participate in the study were excluded. Validity and reliability was done by extensive literature review and followed by consultation with experts while developing of interview guidelines. Pre-designed questionnaires were used and were also pre-tested. The questionnaires had semi-structured, open-ended and closed questions which includes;

1. Socio-demographic characteristics (to know the distribution of study population according to different indicators).

2. Approach to the hospital and doctors.

3. Out-patient department timings and processes of registration.

4. Services provided and behavior by the health care providers.

The data collected through interviews were recorded and analyzed by using Microsoft excel and IBM SPSS Statistics version 20. Descriptive statistics were applied, using frequencies and cross-tabulations. All participants were explained about the nature of the study before proceeding further. Confidentiality was ensured by not disclosing the identity of participants and informed consent was taken from all. 
All of the interviews were conducted by the primary investigator. Sindhi language was used for interviews, which allow communication between researcher and information provider and this also reduces the misunderstanding between interviewees and interviewers.

\section{Results}

The study population consisted of 100 patients meeting the inclusion criteria. Table-1 revealed that majority of the patients $(78 \%)$ belongs to the reproductive age (18-59). Forty seven percent respondents were females while $53 \%$ were males. About one fourth (23\%) patients were single, while $59 \%$ were married. Literacy rate was $73 \%$, including more than one third (35) with higher secondary and above education. On categorizing by patients occupation, it was observed that $37 \%$ were in service, $26 \%$ unemployed, $23 \%$ were labourer and $14 \%$ were students.

Table-2 shows that the overall satisfaction level of patients for availability of health services in the hospital were good. As location of the hospital and timings of the OPD were convenient to the most of the patients $86 \%$ and $93 \%$ respectively. Similarly, $84 \%$ of patients about cleanliness in OPD and $81 \%$ patients regarding services provided by paramedical staff, were found satisfied. Availability of the doctors was also found adequate. However, regarding seating arrangements one fourth of the total patients were found to be unsatisfied. We did not observed patient satisfaction difference between males and females. However, older patients (60 and above) were found more satisfied than other age groups.

Compliance of the patients in respect to the clinical care was more towards the satisfactory side Table-3. As it was $88 \%$ for approach by the doctor, $83 \%$ for good communication by the doctor and $79 \%$ explanation about the disease provided by the doctor to the patient. Efficiency of the doctor was found satisfactory by $83 \%$, while majority of the patients did not faced any kind of language problem.

\section{Discussion}

One of the primary aims of dental treatment is to win the patients' satisfaction and it is an important criterion for judging the success and quality of dental care delivered $^{[7,8]}$. Patient satisfaction is one of the most important quality indicator(s) at the health care institutions. Satisfaction is achieved when the patients' perception of the quality of care and services that they receive in healthcare setting has been positive, satisfying, and meets their expectations ${ }^{[0]}$. Patient satisfaction is relatively new area of study in health system researches especially in Pakistan and is based on patients' perception of the treatment. This study was conducted to focus on various aspects of health care in a newly established dental institution and thereby find solutions to bring positive change or improvement in the health facilities.

The result of our study shows that patients were satisfied with the services and care provided at hospital. Similar kind of study was conducted in Pakistan Railway Hospital Rawalpindi ${ }^{[10]}$ showed same pattern of patients' satisfaction. The best rated was doctors' availability and courteousness (98.3\%) and 96.8\% were satisfied with the attitude of nursing staff. Shakhi MR et al ${ }^{[11]}$ reported that $94.4 \%$ patients were satisfied with hospital services in their study conducted in provincial teaching hospital in Ghazvin Iran.

The study ${ }^{[12]}$ on out patient satisfaction at a super specialty hospital in India, had reported that, as much as $50 \%$ of the patients were satisfied with regard to the cleanliness of the hospital. In another study by Prasanna K S. et $\mathrm{al}^{[13]}$, on consumer satisfaction about hospital services: A study from the outpatient department of a private medical college hospital at Mangalore, it was shown that patients were fully satisfied in respect to seating arrangement, cleanliness in the OPD and OPD timing, which was almost similar to our study. While satisfaction level regarding services by the availability of doctor in hospital, paramedical staff and finding the specialist in the department in OPD were 99\%, 88\% and $84 \%$ respectively. The findings of the study by Hassan Soleimanpour et al[14], on emergency department patient satisfaction survey in Imam Reza Hospital, Tabriz, Iran revealed that the satisfaction level of patients in regard to the information given by care provider about medication was very good in $49.4 \%$ of patients.

The study ${ }^{[15]}$ in a tertiary care teaching hospital in Pakistan on patient satisfaction: A comparative study at teaching versus DHQ level hospital in Lahore, Pakistan; noted that location of hospital was convenient in $38 \%$ of patients for teaching hospitals and $42 \%$ of patients for DHQ level hospital; while $80 \%$ of patients in teaching and 95\% in DHQ level hospital 
were satisfied with the time waited by them to be seen by doctor. And regarding satisfaction level of patients with the amount spent for medical needs, medications available free of cost in the hospital were $74 \%$ and $76 \%$ for teaching hospitals, and $95 \%$ each for DHQ level hospital respectively.

Most of the patients were satisfied from the behavior of doctors and staffs but wanted more awareness against dental diseases and their prevention. A survey in New Zealand ${ }^{[16]}$ showed that almost all the patients wanted to be informed in detail about their dental treatment. Similarly, Rankin and Harris ${ }^{[17]}$ reported that $97 \%$ of the patients surveyed favored a dentist who explained what the treatment and procedure entailed.

We observed that patients, in particular the uneducated and the elderly found it difficult to reach to the sections to which they were referred. They suggested that placing sign boards and volunteers would ease the situation. Patients felt, many a time they were not given any appropriate explanations for the delay in the treatment. Some of the patients commented that there were instances when they or other patients around them were sent back or recalled later because the doctor/house-surgeon/student allotted to the patient were not there.

Satisfaction with the quality of care provided is a very sensitive issue, but little work has been done in this country about this important aspect of patient care. One reason is that we are still struggling for the primary care provision to all of our population rather than talking about its quality. By literature search, we were unable to find any reference about satisfaction with the Dental OPD but reports on satisfaction in some other domains were found. Studies have shown that expectations of patients are based on their experiences, environment, social background and personality ${ }^{[18-21]}$.

This information could be included into undergraduate training curriculum of dentists and continuing education programs. The systematic collections of patients' opinion could help the hospital administration, staff, and dental faculty to get clear idea what their patients are expecting from them.
Table 1: Distribution of respondents based on their socio-demographic characteristics.

\begin{tabular}{lccc}
\hline Characteristics & & No. & Percentage \\
\hline \multirow{3}{*}{ Age } & $18-39$ & 37 & 37 \\
& $40-59$ & 41 & 41 \\
Gender & $60 \&$ above & 22 & 22 \\
& Female & 47 & 47 \\
Marital status & Male & 53 & 53 \\
& Single & 23 & 23 \\
& Married & 59 & 59 \\
Education & Others & 18 & 18 \\
& Graduate \& higher & 7 & 7 \\
& Higher secondary & 28 & 28 \\
& Secondary & 15 & 15 \\
Background & Primary & 23 & 23 \\
& Illiterate & 27 & 27 \\
& Service & 37 & 37 \\
& Labour & 23 & 23 \\
& Unemployed & 26 & 26 \\
& Student & 14 & 14 \\
& Rural & 37 & 37 \\
& Urban & 63 & 63 \\
\hline \multirow{3}{*}{ Occupation } & & &
\end{tabular}

Table-2: Distribution of responses according to availability of the services.

\begin{tabular}{lccc}
\hline Variables & & No. & Percentage \\
\hline \multirow{2}{*}{ Location of the Hospital } & Convenient & 86 & 86 \\
& Inconvenient & 14 & 14 \\
& Convenient & 93 & 93 \\
OPD timings & Inconvenient & 7 & 7 \\
Seating arrangements in & Satisfactory & 73 & 73 \\
OPD & Unsatisfactory & 27 & 27 \\
\multirow{2}{*}{ Cleanliness of the OPD } & Satisfactory & 84 & 84 \\
& Unsatisfactory & 16 & 16 \\
Availability of Doctors & Adequate & 89 & 89 \\
& Inadequate & 11 & 11 \\
Services by paramedical & Satisfactory & 81 & 81 \\
\cline { 2 - 3 } staff & Unsatisfactory & 19 & 19 \\
\hline
\end{tabular}


Table-3: Distribution of responses towards clinical care

\begin{tabular}{lccc}
\hline Variables & & No. & Percentage \\
\hline \multirow{2}{*}{ Approach by the Doctor } & Satisfactory & 88 & 88 \\
& Unsatisfactory & 12 & 12 \\
Communication by the & Satisfactory & 83 & 83 \\
Doctor & Unsatisfactory & 17 & 17 \\
Explanation about the & Satisfactory & 79 & 79 \\
disease to the patient & Unsatisfactory & 21 & 21 \\
Efficiency of the doctor & Satisfactory & 83 & 83 \\
& Unsatisfactory & 17 & 17 \\
Any language problem & Yes & 5 & 5 \\
faced? & No & 95 & 95 \\
\hline
\end{tabular}

\section{Conclusion}

According to patient's opinion, the study revealed that the degree of satisfaction was satisfactory with respect to waiting time and availability of the doctors in the hospital, which need to be further explored and corrected through improvement in different areas of Dental OPD service maintained by repeated monitoring of patient satisfaction. Further, the waiting period of patients for the time of arrival to the time of examination by the doctor must be reduced as far as possible by making the hospital procedures simpler and by guiding them with signboards for different departments.

\section{Conflicting Interests:}

None

\section{Authors' contributions:}

MHS has participated in study design, data entry and analysis, data interpretation, draft writing, editing and submission. MM has participated in data collection, data interpretation and editing. OL has participated in data interpretation and editing. All authors read and approved the final manuscript.

\section{Acknowledgments}

Our deepest appreciations to the patients and staff of the BADC, Larkana, Pakistan for their support during the field work.

\section{Funding}

None.

\section{References}

1. Joshi K, et al., Patient satisfaction about health care services: A cross sectional study of patients who visitthe outpatient department of a civil hospital at Surendrana-gar, Gujarat. International Journal of Medical Science and Public Health, 2013. 2(3): p. 659-663.

2. Laith Alrubaiee and Feras Alkaa'ida. The Mediat-ing Effect of Patient Satisfaction in the Patients' Perceptions of Healthcare Quality - Patient Trust Relationship. International Journal of Marketing Studies. 2011. 3(1): p. 103-127. .

3. V, R., A grounded theory for patients' satisfactionwith quality of hospital care. ICUS NURS WEB J, 2005(22).4. Ameryoun A, et al., Outpatient and inpatientservices satisfaction in Iranian Military Hospitals. IranianRed Crescent Medical Journal, 2013. 15(9): p. 843-847. 5. Penchansky R and T. JW., The concept of access: definition and relationship to consumer satisfaction. Med Care, 1981. 19(2): p. 127-40.

6. Swan JE, et al., Deepening the understanding of hospital patient satisfaction: fulfillment and equity effects. J Health Care Mark, 1985. 5(3): p. 7-18.

7. Habib SR, Ramalingam S, Al Beladi A, Al Habib A. Patients' Satisfaction With The Dental Care Provided By Dental Students. J Ayub Med Coll Abbottabad 2014;26(3).

8. Asghar S, Fatima F, Ali A, Amanat N. Assessmentof patient's satisfaction about dental treatment/facilities provided by Bahria dental college hospital, Karachi. Pakistan Oral \& Dental Journal Vol 33, No. 3 (December 2013).

9. Merican MI, bin Yon R. Health care reform and changes: the Malaysian experience. Asia Pac J Public Health 2002;14:17-22.

10. Khan OA, Iqbal M, Waseem AG. Patient experi-ence and satisfaction with health care at Pakistan Railway hospital, Rawalpindi. Ann. Pak. Inst. Med. Sci. 2012; 8(2): 122-124.

11. Shaikhi MR, Javadi A. Patient satisfaction surveyin medical services in Ghazvin University of medical sciences, Ghazvin, Iran. Journal of Ghazvin University of Medical Sciences 2004, 29: 62-68.

12. Jawahar SK. A Study on Out Patient Satisfactionat a Super Specialty Hospital in India. Internet Journal of Medical Update 2007;2(2):13-7.

13. Prasanna KS, Bashith MA, Sucharitha $S$. Consumer satisfaction about hospital services: A study from the outpatient department of a private medical college hospital at Mangalore. Indian $\mathrm{J}$ Community Med 2009;34(2):156-9. .

14. Soleimanpour H, Gholipouri C, Salarilak S, RaoufiP, Vahidi RG, Rouhi AJ, et al. Emergency department patient satisfaction survey in Imam Reza Hospital, Tabriz, Iran. Int J Emerg Med 2011;4:2. .

15. Tasneem A, Shaukat S, Amin F, Mahmood KT.

Patient satisfaction; a comparative study at teaching versus DHQ level hospital in Lahore, Pakistan. J Pharm Sci \& Res 2010;2 (11):767-74. . 
16. Bishop TG, Flett RD, Beck DJ. A survey of dental health knowledge and attitudes in Owaka, a rural community in South Otaga. NZ Dent J 1975; 71: 185-90. .

17. Rankin JA, Harris MB. Patients' preferences for dentists' behaviors. J Am Dent Assoc 1985; 110: 323-26.

18. Siddiqui $\mathrm{N}$ and Khandaker SA. Comparison of services of public, private and foreign hospitals room the perspective of Bangladeshi patients. J Health Popul Nutr 2007; 25: 221-30. .

19. Van Groenestijn MAJ, Maas-De Waal CJ, Mileman PA et al. The ideal dentist. Soc Sci Med 1980; 14A:533-40. .

20. Davies AR, Ware Jl. Measuring patient satisfac-tion with dental care. Soc Sci Med 1981; 15A: 751-60. .

21. Saaiq M, Zaman K. Pattern of satisfaction among neurosurgical inpatients. J Coll Physicians Surg Pak 2006; 16: 455-9. . 